\title{
Effect of Mild Aerobic Exercise on Lipid and Apolipoprotein Levels in Patients with Essential Hypertension
}

\author{
Yoichi Tanabe, M.D., Jun Sasaki, M.D., Hidenori Urata, M.D., \\ Akira Kryonaga, M.D., Hiroaki Tanaka, M.D.,* \\ Munehiro Shindo, Ph.D., ${ }^{*}$ and Kikuo Arakawa, M.D.
}

\begin{abstract}
SUMmaRY
The effects of supervised mild aerobic exercise at the work load of the blood lactate threshold for 10 weeks on serum lipids and apolipoproteins were studied in 24 patients with essential hypertension. Significant reduction in both systolic and diastolic blood pressure and increased maximal oxygen uptake were observed in both men and women. The high density lipoprotein cholesterol increased significantly following mild aerobic exercise in women. Apolipoprotein A-II was significantly elevated at the 4 th week in women. No significant differences in total cholesterol, triglyceride, low density lipoprotein cholesterol, apolipoproteins A-I, C-II, $\mathrm{C}$-III, $\mathrm{B}$ and $\mathrm{E}$ were observed in either men or women following an exercise program. These data demonstrate the different effect of mild aerobic exercise therapy on high density lipoprotein in hypertensive men and women.
\end{abstract}

\section{Additional Indexing Words:}

Mild aerobic exercise Hypertension Lipids Apolipoproteins

$\mathrm{R}$

EGULAR physical exercise is generally considered to reduce the risk of coronary heart disease by altering plasma lipid and lipoprotein levels. ${ }^{1)-3}$ High density lipoprotein cholesterol (HDL-C) which is reported to be a negative risk factor of coronary artery disease, has been shown to be increased by exercise in men, ${ }^{2,4)-6)}$ but not in women. ${ }^{7-9 /}$ The intensity and the duration of the exercise were important factors in raising the plasma HDL-G level. In this regard, the higher the intensity of the exercise and the longer the duration of the exercise, the greater the increase in HDL-C.

No data are currently available on the effect of mild aerobic exercise (approximately $50 \%$ of maximal oxygen consumption) on lipid and apolipopro-

From the Second Department of Internal Medicine, and the Department of Exercise Physiology,* Fukuoka University, Fukuoka.

Address for reprint: Jun Sasaki, M.D., Second Department of Internal Medicine, Fukuoka University Hospital, 7-45-1 Nanakuma, Jonan-ku, Fukuoka 814-01, Japan.

Received for publication January 14, 1987.

Manuscript revised August 13, 1987. 
tein levels. We have demonstrated that this mild aerobic exercise is effective in the therapy of mild hypertension. ${ }^{10-12}$ The purpose of this study was to examine the serum lipid and apolipoprotein (apo) characteristics following supervised mild aerobic exercise in both male and female patients with essential hypertension.

\section{Materials and Methods}

Twenty-four outpatients (13 males, 11 females) having a diagnosis of essential hypertension (WHO stages I, II) were selected for this study. Their ages ranged from 35 to 60 (average 51) years. No individuals were receiving any antihypertensive agents. Their mean systolic blood pressure was $151 \pm$ $4 \mathrm{mmHg}$ and their mean diastolic blood pressure was $99 \pm 2 \mathrm{mmHg}$. Five hypertensive subjects ( 2 males, 3 females) were followed for 10 weeks without exercise therapy or drugs. All subjects were advised to maintain their previous exercise habits and diet.

To determine exercise intensity, submaximal multistage exercise testing using an electric bicycle ergometer (Lode's Instrumenten B.V., Groningen, Holland) was performed. Blood samples were obtained from the auricle during the test, and the blood lactate levels were measured by a lactate analyzer (Roche 640, Roche Bio-Electronics, Basel, Switzerland). ${ }^{13)}$ Excrcise intensity was determined by plotting blood lactate levels against work load in watts, and the first breaking point of blood lactate ${ }^{14)}$ which is approximately equivalent to $50 \% \quad \mathrm{VO}_{2}$ max was used to define the intensity of training. Training was done 3 times per week, for 10 weeks on a bicycle ergometer (Cyclotek, Monark-Crescent AB, Varberg, Sweden). Training began with a 5 to $10 \mathrm{~min}$ "warm up" period of light calisthenics and stretching exercise followed by a 60 min exercise at a steady speed, and this in turn was followed by a 5 to 10 min " cooling off" period. The exercise sequences were supervised by physical therapists, and pulse rates and blood pressures were monitored during the training periods by a physician. Intellectual work was permitted during exercise. The overall attendance throughout the exercise program was more than $95 \%$. The mean caloric expenditure per session was $280 \mathrm{kcal}$ for men and $210 \mathrm{kcal}$ for women. Blood samples for lipids and apolipoproteins were drawn by venipuncture from the antecubital vein following overnight fasting. Blood samples were obtained before and following 4, 7 and 10 weeks on the exercise program.

The serum was recovered following centrifugation at $3,000 \mathrm{rpm}$ in a clinical centrifuge for $15 \mathrm{~min}$ and stored at $4^{\circ} \mathrm{C}$; analyses were completed within 48 hours. The total cholesterol (TC) and triglyceride (TG) were determined 
enzymatically. ${ }^{151,16)}$ Seronorm lipid (Nyegaard Corp, Oslo, Norway) was used as a standard throughout the study. The coefficients of variation of duplicate determinations were $2.8 \%$ and $3.0 \%$ for $\mathrm{TC}$ and $\mathrm{TG}$, respectively. $\mathrm{HDL}-\mathrm{C}$ was measured by the heparin- $\mathrm{MnCl}_{2}$ precipitation method using a final concentration of manganese chloride of $92 \mathrm{mM}$. Serum apolipoproteins A-I, A-II, B, G-II, C-III and E were determined by single immunodiffusion. ${ }^{17), 18)}$ The intra-assay coefficient of variation for apolipoproteins from a single sample measured in triplicate on the same plate was less than $5 \%$. The differences between mean values were determined by two-tailed paired t-test.

\section{Results}

Both systolic and diastolic blood pressures were decreased significantly

Table 1. Changes in Blood Pressure Following 10 Weeks on a Mild Aerobic Training Program

\begin{tabular}{c|c|c|cc|c}
\hline $\begin{array}{c}\text { Blood pressure } \\
(\mathrm{mmH})\end{array}$ & Sex & $\mathrm{n}$ & \multicolumn{2}{|c|}{ weeks } & Significance \\
\hline Systolic & $\mathrm{M}$ & 10 & $147 \pm 5$ & $139 \pm 6$ & $\mathrm{p}<0.01$ \\
& $\mathrm{~F}$ & 11 & $156 \pm 5$ & $139 \pm 5$ & $\mathrm{p}<0.01$ \\
Diastolic & $\mathrm{M}$ & 10 & $99 \pm 3$ & $95 \pm 5$ & $\mathrm{NS}$ \\
& $\mathrm{F}$ & 11 & $98 \pm 3$ & $91 \pm 4$ & $\mathrm{p}<0.01$ \\
Mean & $\mathrm{M}$ & 10 & $115 \pm 3$ & $110 \pm 5$ & $\mathrm{p}<0.05$ \\
& $\mathrm{~F}$ & 11 & $117 \pm 3$ & $107 \pm 4$ & $\mathrm{p}<0.01$
\end{tabular}

Values are mean $\pm S E M$. NS $=$ not significant.

Table II. Changes in Physical Fitness Following a 10 Week Training Program

\begin{tabular}{|c|c|c|c|c|c|}
\hline & \multirow{2}{*}{ Sex } & \multirow{2}{*}{$\mathrm{n}$} & \multicolumn{2}{|c|}{ weeks } & \multirow{2}{*}{ Significance } \\
\hline & & & 0 & 10 & \\
\hline \multirow[t]{2}{*}{ Body weight $(\mathrm{kg})$} & M & 13 & $70.2 \pm 3.0$ & $70.1 \pm 2.9$ & NS \\
\hline & $F$ & 11 & $53.3 \pm 2.2$ & $53.9 \pm 2.3$ & NS \\
\hline \multirow{2}{*}{$\begin{array}{l}\mathrm{VO}_{2} \max ^{3)} \\
(\mathrm{m} l / \mathrm{kg} / \mathrm{min})\end{array}$} & $M$ & 10 & $27.4 \pm 1.1$ & $31.5 \pm 1.3$ & $\mathrm{p}<0.01$ \\
\hline & $\mathrm{F}$ & 11 & $27.3 \pm 1.9$ & $33.8 \pm 2.6$ & $\mathrm{p}<0.01$ \\
\hline \multirow[t]{2}{*}{$\dot{W} \max ^{b)}$ (watt) } & $M$ & 10 & $107 \pm 7$ & $120 \pm 7$ & $p<0.02$ \\
\hline & $F$ & 11 & $66 \pm 4$ & $82 \pm 5$ & $\mathrm{p}<0.01$ \\
\hline \multirow{2}{*}{$\underset{\text { (watt) }}{\left.\dot{\mathrm{W}} \underset{\mathrm{BPL}}{\mathrm{A}_{1}} \mathrm{c}\right)}$} & $\mathbf{M}$ & 10 & $45 \pm 8$ & $56 \pm 8$ & $\mathrm{p}<0.05$ \\
\hline & $\mathrm{F}$ & 11 & $30 \pm 3$ & $37 \pm 2$ & $p<0.01$ \\
\hline
\end{tabular}

Values are mean \pm SEM. NS= not significant.

a) Maximal oxygen uptake.

b) Maximal work load.

c) Work load at first breaking point of lactate. 
following 10 weeks of mild aerobic exercise training (Table I). There was no change in body weight before and after exercise therapy (Table II). Significantly improved indices of physical fitness were observed in both men and women following 10 weeks of mild aerobic exercise (Table II). No significant changes in lipids, lipoproteins and apolipoproteins were observed over a 10 week period in nonexercising hypertensive controls (Table III). No significant differences in the parameters were observed between males and females in nonexercising hypertensive controls. Lipid, lipoprotein and apolipoprotein profiles of the hypertensive subjects are summarized in Tables IV-VI. The HDL-C levels increased significantly following a mild aerobic exercise program in women (Table IV). Mean apo A-I tended to increase during the exercise program, but this increase was not significant. Apo A-II levels increased significantly by the 4th week of exercise in women, but thereafter the levels were not significantly different from baseline (Table V). Serum TG, apo G-II, apo C-III and apo E all tended to be increased by the 10th

Table III. Changes in Lipids, Lipoproteins and Apolipoproteins in Hypertensive Subjects without Exercise Therapy for 10 Weeks

\begin{tabular}{|c|c|c|c|}
\hline & \multicolumn{2}{|c|}{ weeks } & \multirow{2}{*}{ Significance } \\
\hline & 0 & 10 & \\
\hline $\mathrm{TC}(\mathrm{mg} / \mathrm{dl})$ & $193 \pm 7$ & $193 \pm 16$ & NS \\
\hline HDL-C (mg/dl) & $55 \pm 4$ & $55 \pm 3$ & NS \\
\hline LDL-G $(\mathrm{mg} / \mathrm{dl})$ & $115 \pm 9$ & $119 \pm 12$ & NS \\
\hline $\mathrm{TG}(\mathrm{mg} / \mathrm{dl})$ & $111 \pm 28$ & $96 \pm 22$ & NS \\
\hline Apo A-I (mg/dl) & $143 \pm 9$ & $152 \pm 6$ & NS \\
\hline Apo A-II (mg/dl) & $33 \pm 2$ & $35 \pm 3$ & NS \\
\hline Apo B $(\mathrm{mg} / \mathrm{dl})$ & $100 \pm 11$ & $103 \pm 9$ & NS \\
\hline Apo C-II $(\mathrm{mg} / \mathrm{dl})$ & $3.8 \pm 0.7$ & $4.1 \pm 0.6$ & NS \\
\hline Apo C-III ( $\mathrm{mg} / \mathrm{dl})$ & $8.3 \pm 1.0$ & $8.6 \pm 1.2$ & NS \\
\hline Apo $\mathrm{E}(\mathrm{mg} / \mathrm{dl})$ & $5.3 \pm 0.8$ & $4.9 \pm 0.5$ & NS \\
\hline
\end{tabular}

Values are mean $\pm S E M$. NS $=$ not significant.

Hypertensive subjects include 2 males and 3 females.

Table IV, Effect of Mild Exercise on Serum Cholesterol

\begin{tabular}{l}
\hline \multirow{2}{*}{} \\
\cline { 2 - 8 }
\end{tabular}


week following initiation of the exercise program $(p<0.01)$. No significant changes were observed in TC, apo B, apo C-II, apo C-III or apo E (Tables IV-VI) in either men or women.

\section{Discussion}

Patients with essential hypertension were subjected to mild aerobic exercise therapy for 10 weeks which resulted in significantly lowered systolic and diastolic pressures and increased $\dot{\mathrm{V}}_{2}$ max in both men and women, reconfirming our previous observations. ${ }^{10)-12}$ ) In addition, significantly increased concentrations of HDL-C and apo A-II were observed in women. At the same time, apo A-I, which is a major apoprotein of HDL, tended to increase in the exercising women, but was not statistically different by 10 weeks. These data suggest that compositional changes in HDL were occurring following mild aerobic exercise in women.

Several previous investigations have reported high serum HDL-C levels in subjects who practice vigorous physical exercise, ${ }^{5), 6(19)}$ but no change was observed in another study. ${ }^{9}$ ' Recently, it has been reported that moderate aerobic exercise of much lower intensity is sufficient to influence the level of HDL-C in male myocardial infarction survivors. ${ }^{20)}$ The present study demonstrated that even mild aerobic exercise can increase the HDL-C level in women. However, the level of HDL-C was constant in men during the 10 week mild aerobic exercise training period. In contrast, Lewis et al reported an increased level of HDL-C in men and not significant changes in women, ${ }^{8}$ and Brownell et al observed no significant changes in HDL-C in either men or women following moderate aerobic exercise for 12 weeks. ${ }^{9}$

In the results reported in this manuscript, an increased HDL-G level was observed in women, whereas no changes were observed in men. The reason for this discrepancy remains unknown. Our previous data suggest a positive correlation between $\dot{\mathrm{O}}_{2}$ max and HDL-C. ${ }^{21}$ In the present study, women showed a greater increase in $\dot{\mathrm{VO}}_{2} \max (24 \%)$ than did men $(15 \%)$, while the

and Triglyceride Levels in Hypertensive Subjects

\begin{tabular}{|cccc|cccc}
\hline \multicolumn{3}{|c|}{$\begin{array}{c}\text { LDL-cholesterol (mg/dl) } \\
\text { wceks }\end{array}$} & \multicolumn{4}{c}{$\begin{array}{c}\text { Triglyceride }(\mathrm{mg} / \mathrm{dl}) \\
\text { weeks }\end{array}$} \\
\hline 0 & 4 & 7 & 10 & 0 & 4 & 7 & 10 \\
\hline $127 \pm 7$ & $118 \pm 6$ & $129 \pm 9$ & $122 \pm 8$ & $130 \pm 20$ & $106 \pm 29$ & $137 \pm 25$ & $120 \pm 33$ \\
$150 \pm 10$ & $148 \pm 10$ & $146 \pm 9$ & $153 \pm 15$ & $126 \pm 13$ & $124 \pm 27$ & $125 \pm 24$ & $141 \pm 23$
\end{tabular}




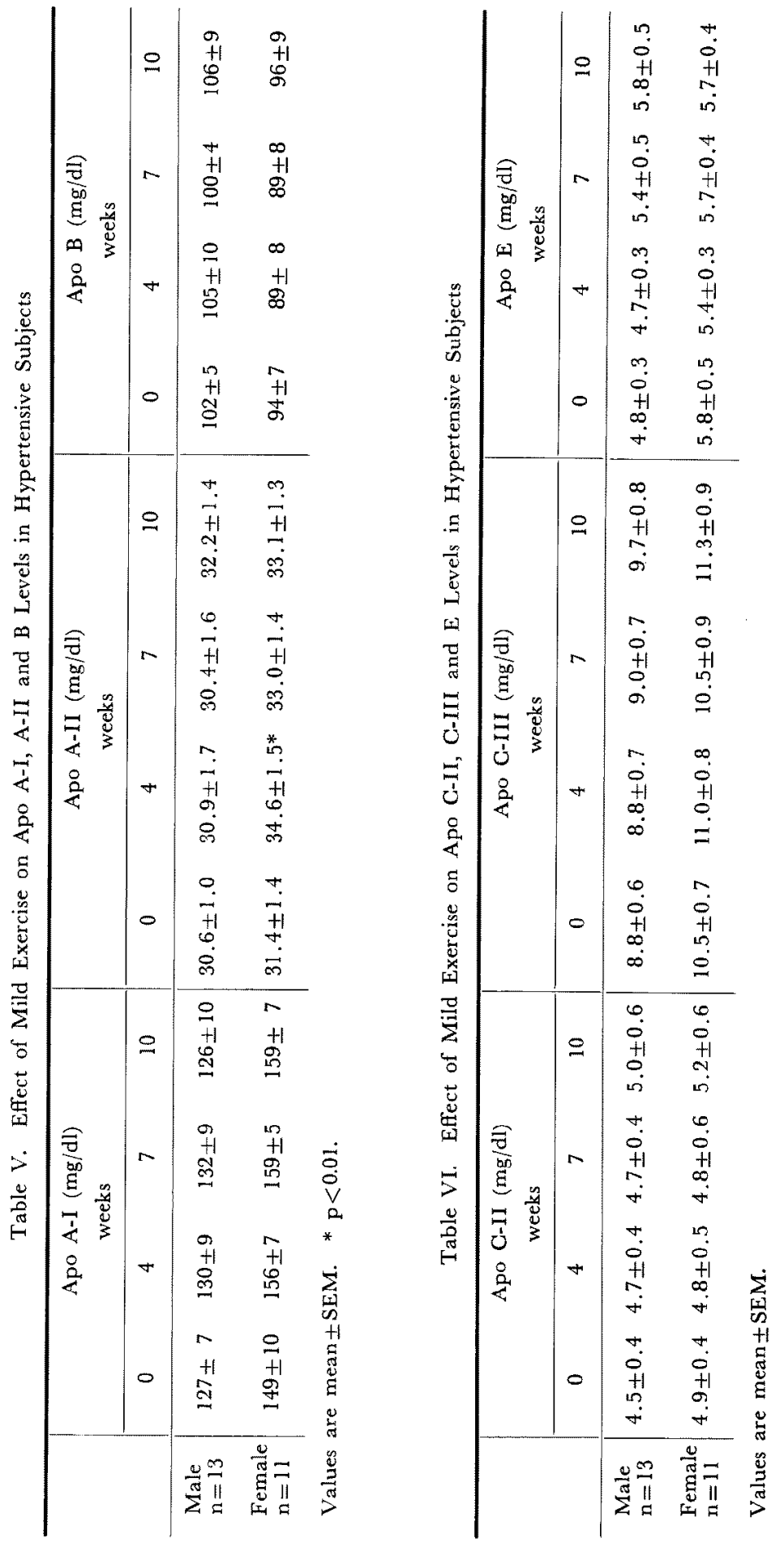


initial values of $\dot{\mathrm{V}}_{2}$ max did not differ between men and women. Therefore, the different response in aerobic capacity following this mild exercise program may have resulted in the different changes in HDL-C level. Furthermore, the exercise intensity used in this study was lower than previously reported exercise programs and the intensity of exercise resulted in fat being used as the primary energy source. Thus, the intensity of the exercise may, in part, explain the differences in responses of lipoprotein metabolism between men and women following mild aerobic exercise.

The possibility that the observed changes in lipids and apolipoproteins in this study might be mediated by other factors such as diet or altered body composition cannot be excluded. However, according to the dietary questionnaire administered regularly to the patients, their food consumption was not changed.

\section{REFERENCES}

1. Holloszy JO, Skinner JS, Toro G, Cureton TK: Effects of a six month program of endurance exercise in the serum lipids of middle-aged man. Am J Cardiol 14: 753, 1964

2. Streja D, Mymin D: Moderate exercise and high-density lipoprotein-cholesterol. JAMA 242: 2190,1979

3. Hartung GH, Squires WG, Gotto AM: Effect of exercise training on plasma high-density lipoprotein cholesterol in coronary disease patients. Am Heart J 101 : 181, 1981

4. Leon AS, Conrad J, Hunninghake DB, Serfass R: Effects of a vigorous walking program on body composition, and carbohydrate and lipid metabolism of obese young men. Am J Clin Nutr 32: 1776, 1979

5. Lopez A, Vial R, Balart L, Arroyave G: Effects of exercise and physical fitness on serum lipids and lipoproteins. Atherosclerosis 20: 1, 1974

6. Huttunen JK, Lansimies E, Voutilainen E, Ehnholm G, Hietanen E, Penttila I, Siitonen O, Rauramaa R: Effect of moderate physical exercise on serum lipoproteins. Circulation 60: 1220,1979

7. Ballantyne D, Clark A, Dyker GS, Gillis CR, Hawthorne VM, Henry DA, Hole DS, Murdoch RM, Semple T, Stewart GM: Prescribing exercise for the healthy: assessment of compliance and effects on plasma lipids and lipoproteins. Health Bull 32: 169, 1978

8. Lewis S, Haskell WL, Wood PD, Manoogian N, Bailey JE, Pereira M: Effects of physical activity on weight reduction in obese middle-aged women. Am J Clin Nutr 29: 151, 1976

9. Brownell KD, Bachorik PS, Ayerle RS: Changes in plasma lipid and lipoprotein levels in men and women after a program of moderate exercise. Circulation 65: 477, 1982

10. Arakawa K, Kiyonaga A, Shindo M, Tanaka H: The beneficial effect of exercise therapy for essential hypertension and a probable mechanism. A preliminary report. in Nutritional Prevention of Cardiovascular Disease, ed by Lovenberg W, Yamori Y, Academic Press, New York, p 349, 1984

11. Arakawa K, Kiyonaga A, Shindo M, Tanaka H: Antihypertensive effect of aerobic exercise therapy and plasma renin activity. Circulation 70: II-63, 1984

12. Kiyonaga A, Arakawa $\mathrm{K}$, Tanaka $\mathrm{H}$, Shindo $\mathrm{M}$ : Blood pressure and hormonal responses to aerobic exercise. Hypertension 7: 125, 1985

13. Soutter WP, Sharp F, Clark DM: Bedside estimation of whole blood lactate. Br J Anaesth 50: 445,1978 
14. Ivy JL, Withers RT, Van Handel PJ, Elger DH, Costill DL: Muscle respiratory capacity and fiber type as determinants of the lactate threshold. J Appl Physiol 48: 523, 1980

15. Allain CC, Poon LS, Chan CS, Richmond W, Fu PC: Enzymatic determination of total serum cholesterol. Clin Chem 20: 470, 1974

16. Eggstein M, Kreutz FH: Eine neue Bestimmung der Neutralfette im Blutserum und Gewebe. I. Mitt (Prinzip, Durchfuhrung und Besprechung der Methode). Klín Wochenschr 44: 262, 1966

17. Cheung MC, Albers JJ: The measurement of apolipoprotein A-I and A-II levels in men and women by immunoassay. J Clin Invest 60:43, 1977

18. Sakai Y, Itakura K, Kanda T, Ebata N, Suga K, Aikawa H, Nakamura K, Sata T: Quantitation of apolipoprotein A-I in pooled human serum by single radial immunodiffusion and sodium dodecyl sulfate polyacrylamide gel electrophoresis. Anal Biochem 137: 1, 1984

19. Altekruse $\mathrm{EB}$, Wilmore JH: Changes in blood chemistries following a controlled exercise program. J Occup Med 15: 110, 1973

20. Ballantyne FC, Glark RS, Simpson HS, Ballantyne D: The effect of moderate physical exercise on the plasma lipoprotein subfractions of male survivors of myocardial infarction. Circulation 65: 913, 1982

21. Murakami H, Shindo M, Tanaka H, Kumagai S, Ikuta S, Sasaki J: Significance of predicted maximal oxygen uptake as a coronary atherosclerotic heart disease risk factor. J Jpn Atheroscler Soc (in Japanese with English abstract, in press) 